\title{
Urgences
}

\section{Naissances : échos}

\section{Pierre Julien}

Numéro 29, octobre 1990

\section{Éclats d'œuvre}

URI : https://id.erudit.org/iderudit/025607ar

DOI : https://doi.org/10.7202/025607ar

Aller au sommaire du numéro

\section{Éditeur(s)}

Urgences

\section{ISSN}

0226-9554 (imprimé)

1927-3924 (numérique)

Découvrir la revue

\section{Citer ce document}

Julien, P. (1990). Naissances : échos. Urgences, (29), 67-69.

https://doi.org/10.7202/025607ar d'utilisation que vous pouvez consulter en ligne.

https://apropos.erudit.org/fr/usagers/politique-dutilisation/ 


\section{Naissances: échos \\ Pierre Julien}

\section{La vie}

Naissance assassine. En me donnant la vie, ma mère m'a cédé la sienne. Bien sûr, cette façon peu élégante de commencer une vie nous «condamne à vivre avec des points d'interrogation tout autour de nous». Mais j'ai mis fin à mon tourment lorsque j'ai pris conscience que celui et celle qui voulaient avoir un autre enfant savaient ce qu'ils faisaient. S'ils m'avaient consulté, je les aurais dissuadés de leur projet, du fait que ma mère avait déjà accouché d'un enfant mort-né, que, née maladive, l'aînée est morte à l'âge de deux ans et que, née chétive, la cadette a eu toutes les peines du monde à franchir huit mois de vie. Ce n'est pas parce que mon frère aîné a traversé indemne le premier col de sa vie, que la santé délicate de ma mère s'est améliorée. Bien au contraire... Je décline donc toute responsabilité dans cette triste affaire.

\section{La plâtre}

Début juillet 1983, Ruisseau Leblanc, près de Bonaventure. Trois automobiles entrent en collision: un mort et six blessés. Je suis le moins amoché. Le médecin me condamne à deux mois et demi de fauteuil roulant. Deux mois et demi de lecture: un cadeau du ciel. À moi Yourcenar, Tournier, Dostoïevski et bien d'autres. Cela me changeait des textes de loi et de jurisprudence que je devais me taper, même durant les fins de semaine. À cette époque, je plaidais des griefs en arbitrage, négociais des conventions collectives et dirigeais des grèves sur un territoire plus grand que celui de la Suisse. Chacun de ces soixante-douze jours m'étant aussi précieux qu'inespéré, je n'ai presque rien lu de nouveau. Je ne voulais pas perdre, ne serait-ce qu'une toute petite heure, en hasardant une aventure qui ne m'aurait peut-être pas plu. Pourquoi risquer Les frères Karamazov quand je savais depuis l'âge de seize ans que Crime et 
68

châtiment m'exaltait? Pourquoi tenter Mémoires d'Hadrien quand L'œuvre au noir avait déjà fait mon enchantement? Je me berçais douze heures par jour dans mes valeurs refuges, avalant une petite galimafrée par-ci, par-là... tout en continuant à lire au point que des gens se demandaient si cet accident ne m'avait pas troublé l'esprit. Je savais que cet accident me permettrait de retrouver mon équilibre, la fureur de lire compensant la fureur de vivre en fou, toujours sur la route d'une ville à l'autre et n'apparaissant chez nous que pour changer de valise. Ce beau coup du sort, il me le fallait. Je l'ai eu. L'ai-je inconsciemment provoqué? Pourtant non, puisque ce n'est pas moi qui conduisais.

\section{La mort}

Mon grand-père? Un livre d'histoire entré à 26 ans dans le $\mathrm{XX}^{\mathrm{e}}$ siècle. Il ne disait pas Ontario, Québec, Vietnam et Thaïlande mais Haut et Bas-Canada, Tonkin et Siam. Il ne prenait pas l'autobus mais l'impériale ou l'omnibus. Il n'aimait pas la reine Victoria sous le long règne de laquelle son grand-père et lui avaient vécu: le pouvoir qu'elle représentait avait condamné à mort son grand-père. Il m'a montré le texte de la sentence dont j'ai appris par cœur les deux dernières lignes: «for those reasons, Louis Julien is condamned to be hang by the neck, high and short and until he dies. * Puis le juge a livré la séance en disant en français: "C'est tout. * Mon aïeul a répliqué: «C'est ben assez."

Un jour de 1927, il dit à ma grand-mère, âgée comme lui de 54 ans: *Angélina, nous assistons à l'événement technique le plus spectaculaire de toute l'histoire de l'humanité: y paraît qu'un nommé Charles Lindberg vient de traverser l'océan Atlantique à bord d'une machine volante. On aura ben tout vu. * Il ne se doutait pas qu'un jour, dans 36 ans, il verrait de ses propres yeux, et dans son salon encore, Youri Gagarine rentrer triomphalement de l'espace. S'il avait vécu deux ans de plus, il aurait vu trois hommes marcher sur la lune, mais quand il a admis que la science n'avait pas de fin, il a réclamé la sienne. Elle ne venait pas. Il nous disait: « Le bon Dieu m'a oublié.»

Puis un jour, la religieuse qui s'occupait de lui trouva que sa petite sieste d'après-dîner durait longtemps. Elle 
ouvrit les rideaux et le vit, couché dans son lit sur le dos, habit, cravate, souliers, ses * verres * sur le nez, son chapelet enroule autour de ses mains jointes et une expression de sérénité fixée dans ses traits. Il avait 92 ans. 